he took terfenadine $50 \mathrm{mg}$ once a day for hay fever concurrently with fluoxetine $20 \mathrm{mg}$ once a day and experienced orgasms on several occasions. He also reported anergia and mild drowsiness while taking this combination of drugs. Despite remission of his hay fever symptoms the patient chose to remain on terfenadine in order to counterbalance the unwanted sexual side-effects of fluoxetine.

Fluoxetine has been reported to cause sexual dysfunction. The cause of this is unclear but may be related to stimulation of the serotonergic system (Aizenberg et al, 1995). A number of adjunctive pharmacological strategies including yohimbine, cyproheptadine, bethanechol, amantidine, and bupropion have been employed previously for the treatment of this dysfunction (Labette \& Pollack, 1994). There are no published reports of restoration of normal sexual function with the use of terfenadine. Terfenadine is an antihistamine and has no reported effect on serotonergic function. Thus, our patient's recovery of sexual function appears to be due to the peripheral action of terfenadine. Terfenadine and its active metabolite fexofenadine do not cross the blood-brain barrier. Thus, an antihistaminic effect may be important in resolution of serotonergic-induced sexual dysfunction.

Fluoxetine inhibits cytochrome P450 (Nemeroff et al, 1996) which metabolises terfenadine. This causes an elevation in plasma levels of terfenadine when used in conjunction with fluoxetine. Cardiac toxicity has been observed in patients taking fluoxetine and terfenadine concurrently (Marchiando et al, 1995). Therefore, we would recommend caution in the treatment of fluoxetine-induced sexual dysfunction with terfenadine.

Aizenberz, D., Zemishlam, Z. \& Wizman, A. (1995) Cyproheptadine treatment of sexual dysfunction induced by SSRI. Clinical Neuropharmacology 18, 320-324.

American Poychlatric Association (IS4) Diagnostic and Statistical Manual of Mental Disorders (4th edn) (DSM-N). Washington, DC: APA.

Labatte, L. A. \& Pollack, M. H. (1994) Treatment of fluoxetine induced sexual dysfunction with bupropion: a case report. Annois of Clinicol Psychiotry, 6, 13-15.

Marchiando, R. J., Cook, M. D. \& Jwe, S. G. (1995) Probable terfenadine-fluoxetine associated cardiac toxicity (letter). Annols of Phormacotherapy, 29.937-938.
Nomerof, C. B., Dovane, C. L. \& Pollock, B. G. (19\%6) Newer antidepressants and the cytochrome P450 system. American journal of Psychiatry, 153. 311-320.

A. Valmana Department of Psychiatry. St George's Hospital Medical School, Cranmer Terrace, London SWI7 ORE

P. Purcell Haleacre Unit, Amersham Hospital, Whielden Street, Amersham, Bucks HP7 0JD

\section{Data on the Mental Health Act}

Sir: We have been commissioned by the Department of Health to perform a systematic review of all data pertaining to the Mental Health Act 1983. In order to avoid publication bias, we invite any readers who have unpublished data (including audits into the use of the Act) to contact us so their data can be included in the final report. Readers with such data should contact Ms Wall at the address below, or electronically on: s.wall@iop.bpmf.ac.uk.

S. Wall, R. Churchill, M. Hotopf Department of Psychological Medicine, King's College School of Medicine and Dentistry and Institute of Psychiatry. 103 Denmark Hill, London SES 8AZ

\section{Complementary medicine discussion group}

Sir: I wish to contact Members and Fellows with a special knowledge of complementary (or alternative) medicine who would be interested in forming a discussion group on aspects of this topic related to the education and guidance of psychiatrists and general practitioners.

Recent surveys in several countries that possess extensive modern health services show that complementary treatments are used by as many as a third of the adult population more than once, or even regularly. In addition, estimates suggest that the total amount of money spent on complementary treatments is of the same order of magnitude as that spent on orthodox medicines.
The large size of this industry means that many patients seen by doctors of all types must also be using some form of complementary treatment, and this applies particularly to people with long-standing illnesses who are often being cared for by psychiatrists.

The initial purpose of a discussion group would be to try to identify some reading matter which would help psychiatrists to offer some useful guidance to patients who ask them about complementary treatments, or who turn out to be using both orthodox and complementary treatments at the same time. At the moment very few medical schools or postgraduate courses in psychiatry even mention this subject in the programmes offered to trainees. Many psychiatrists might be glad of some guidance, so long as it is seen to be on the cautious side.

It needs to be made clear from the outset that the purposes of such a discussion group would include neither the recommendation nor the rejection of complementary treatments as a whole, since the term as used at present covers a very wide variety of different treatments and procedures. Depending on the circumstances, some are potentially useful, but others are likely to be useless or even harmful.

I should be interested to hear from Members and Fellows who already have some knowledge of the topic and who are interested in a cautious but constructive approach with the first objectives as outlined above.

In view of the potentially controversial nature of this topic and the rather definite viewpoints that are likely to be encountered, I am taking this first step as an individual rather than as a member of a Department of Psychiatry or of a Faculty of the Royal College. If the early stages go well, it is just possible that any discussion group formed might be regarded as within the Faculty of General and Community Psychiatry of the College, but at this stage this is only a conjecture.

J. Cooper 25 Ireton Grove, Attenborough, Nottingham NG9 6B] 